\title{
Foreclosing Competition through High Access Charges and Price Discrimination ${ }^{1}$
}

\author{
Ángel L. López ${ }^{2}$ and Patrick Rey ${ }^{3}$
}

2 April 2015

\footnotetext{
${ }^{1}$ This paper has benefited from helpful comments from Albert Banal-Estañol, Giulio Federico, Doh-Shin Jeon, Bruno Jullien, Gerard Llobet, Tommaso Valletti and an anonymous referee, as well as conference participants at the XXIV Jornadas de Economía Industrial (Vigo, 2009), EARIE (Ljubljana, 2009), EEA (Barcelona, 2009), Conference on the Economics of ICT (Telecom ParisTech, 2009) and seminar audiences at FEDEA, IESE, Universitat Pompeu Fabra and the Florence School of Regulation. Ángel López gratefully acknowledges the financial support from the Spanish Ministry of Science and Technology under ECO2008-05155 and ECO2011-29533, and from Juan de la Cierva Program. Patrick Rey gratefully acknowledges the financial support from the European Research Council (ERC) under the European Community's Seventh Framework Programme (FP7/2007-2013) Grant Agreement N 340903.

${ }^{2}$ Departament d'Economia Aplicada (Universitat Autònoma de Barcelona), and PublicPrivate Sector Research Center (IESE Business School); email: angelluis.lopez@uab.cat.

${ }^{3}$ Toulouse School of Economics (GREMAQ and IDEI, Allée de Brienne 31000 Toulouse; email: patrick.rey@tse-fr.eu
} 


\begin{abstract}
This article analyzes competition between two asymmetric networks, an incumbent and a new entrant. Networks compete in non-linear tariffs and may charge different prices for on-net and off-net calls. When access charges are high, this allows the incumbent to foreclose the market in a profitable way if switching costs are sufficiently large. In the absence of termination-based price discrimination, however, such foreclosure strategies are not profitable.
\end{abstract}




\section{Introduction}

Telecommunication networks need to access rivals' customers in order to provide universal connectivity. Hence the same network operators that compete at the retail level for subscribers, must also cooperate at the wholesale level, where they must agree on access conditions and, in particular, on the level of the access charge (also called termination charge) for terminating each other's calls. In this setting, we explore the concern that high access charges may allow incumbent operators to foreclose the market.

So far, most of the literature has instead focused on the concern of "excessive" cooperation. Armstrong (1998) and Laffont, Rey and Tirole (1998a) showed for instance that when networks compete in uniform, linear prices, then they can soften this competition by agreeing on a high reciprocal access charge: Raising the access charge increases the marginal cost of calls, which encourages operators to maintain high prices. Since then, the analysis has been enriched to allow for non-linear retail pricing, termination-based price discrimination, or dynamic competition. ${ }^{1}$ Interestingly, when non-linear retail tariffs are considered, most of this literature finds that network operators would favor low (even below cost) access charges, in stark contrast with the policy debate where in practice, operators have been resisting regulatory pressures to decrease termination rates. ${ }^{2}$

Yet, in markets where large incumbent operators face competition from smaller rivals, antitrust and regulatory agencies have voiced the concern that cooperation may rather be "insufficient." The concern stems from tariff-mediated network effects, i.e., situations where consumers have a preference for joining a popular network, purely due to the price structure of calls. The logic is that if the access charge is above cost, then prices are higher for "off-net" calls (i.e., those to subscribers on other networks) and, as a result, customers will favour larger networks, in which a higher proportion of calls remain "onnet" (i.e., on the same network). For example, in their Common Position the European regulators not only argue in favour of symmetric access charges but also express the concern that, because of network effects, "an on-net/off-net retail price differential, combined with significantly above-cost [access charges], can, in certain circumstances, tone down competition to the benefit of larger networks". ${ }^{3}$ Similar concerns have been voiced in national decisions. ${ }^{4}$

\footnotetext{
${ }^{1}$ See for instance Laffont, Rey and Tirole (1998a,b), Gans and King (2001), De Bijl and Peitz (2002, 2004), and López (2008). For a review of this literature, see Armstrong (2002), Vogelsang (2003), and Peitz, Valletti and Wright (2004).

${ }^{2}$ We discuss further this literature and possible solutions to this puzzle in Section 7.

${ }^{3}$ See ERG (2008) at p. 97. The Common Position also stresses that these network effects can be exacerbated via incoming calls: as a high off-net price reduces the amount of off-net calls, it also lowers the value of belonging to the smaller network since less people will then call the customers of that network.

${ }^{4}$ See for example, the French regulator's decision of October 2007 (Section 4.2.2 of ARCEP Decision 2007-0810 of October 4 2007) and the Spanish regulator's decision of September 2006 (Decision AEM 2006/726, pp. 13-14 and 33).
} 
To explore this issue, we examine competition between two asymmetric networks, an incumbent and a new entrant, for a given reciprocal access charge. ${ }^{5}$ Customers are initially attached to the incumbent network and incur switching costs if moving to the other network. ${ }^{6}$ Thus, as in Klemperer (1987), to build market share the entrant must bid more aggressively for customers than the incumbent, which enjoys greater market power. Of course, the incumbent operator could keep monopolizing the market if switching costs were large enough. But as we will see, even when switching costs are not that large, high access charges can help the incumbent operator maintain its monopoly position and profit.

We first consider the case where networks not only compete in subscription fees and in usage prices, but can moreover charge different prices for on-net and off-net calls. In the case of symmetric networks, building on Laffont, Rey and Tirole (1998b), Gans and King (2001) show that a (reciprocal) access charge below cost reduces competition and raises the firms' profit. We show that, in the case of asymmetric networks, this carries only so long as the two networks share the market. By contrast, a large enough access charge enables the incumbent operator to corner the market, in which case its profit increases with the access charge. The maximum profit that it can obtain in this way depends however on the degree of product differentiation as well as on the magnitude of switching costs and network effects. In particular, foreclosure is profitable if switching costs are not too low, products are not too differentiated and network effects are large enough. We also discuss welfare effects: Increasing the access charge reduces the value of off-net calls, a negative effect however compensated by the expansion of the market share of the dominant operator (which reduces the proportion of off-net calls).

We then show that price discrimination between on-net and off-net calls is a key factor for foreclosure. Indeed, absent such on-net pricing, foreclosing the market through high access charges is never profitable - it is moreover no longer feasible in a "receiver-pays" regime, i.e., when network operators also charge for call receptions. Thus, the pricemediated network effects stemming from on-net pricing are essential for the incumbent operator to profitably keep the entrant out of the market and still charge monopoly prices.

Despite the concerns voiced by regulators, few papers have studied the role of mobile termination rates in foreclosing entry. Calzada and Valletti (2008) and Hoernig (2007) however explore this issue and their work is thus most closely related to ours. Calzada and Valletti (2008) first consider a symmetric oligopoly and show that, as with two firms, equilibrium profits decrease with the access charge. Building on this insight, they stress that incumbent operators may still favour above-cost access charges, in order to deter

\footnotetext{
${ }^{5}$ In most countries access charges are indeed symmetric, due either to bilateral agreements or regulatory intervention. [Some regulators have let new entrants charge slightly higher termination rates for a limited period of time, but such rate asymmetry has progressively been phased out.]

${ }^{6}$ Grzybowski (2008) find that consumers of mobile services in UK face significant switching costs. Grzybowski and Pereira (2011) also find large switching costs in the Portuguese mobile market.
} 
entry: While doing so decreases ex post the profit of the incumbents, for any given number of market participants, from an ex ante standpoint it may constitute a profitable strategy, by limiting the number of entrants. This however requires the incumbent operators to commit themselves not to modify ex post the access charge; otherwise, the incumbent operators would have an incentive to decrease the access charge and, anticipating that, potential competitors would enter the market. By contrast, in our analysis the dominant operator finds it profitable to foreclose the market through a high access charge, even from an ex post standpoint - in particular, our setting allows the smaller operator to remain "in the market" and exert a competitive pressure even if it is foreclosed. Our analysis thus does not require any commitment assumption.

Hoernig (2007) analyzes the impact of call externalities (namely, taking into account the utility of receiving calls) on the equilibrium price structure. He first shows that such call externalities yield higher on-net/off-net price differentials, even in the absence of anti-competitive intent. He then shows that predatory motives would induce even greater on-net/off-net price differentials: That is, increasing this differential is the "least costly way" (in terms of sacrificed profit), for the dominant operator, to inflict a given loss of profit on its smaller rival. Assessing the profitability of these predation scenarios would however involve a comparison between the short-term sacrifice of profit and the long-term benefit from reduced competition. By contrast, our analysis shows how foreclosure can arise even in a static framework.

The article is organized as follows. Section 2 describes the model. The next two sections analyze the impact of a (reciprocal) access charge on retail competition: Section 3 shows that, as long as the market remains shared, an increase in the access charge reduces profits; Section 4 shows however that on-net pricing and a high enough access charge enables the incumbent operator to profitably foreclose the market. Section 5 illustrates the main insights by means of a simple example. Section 6 analyses the case of no termination-based price discrimination under both the caller-pays and the receiverpays regime. Section 7 concludes.

\section{The model}

There are two network operators: an incumbent, $I$, and an entrant, $E$. The two operators have the same cost structure: It costs $f$ to set up a customer's service, and each call costs $c \equiv c_{O}+c_{T}$, where $c_{O}$ and $c_{T}$ respectively denote the costs borne by the originating and terminating networks. To terminate an off-net call, the originating network must pay a reciprocal access charge $a$, which is taken to be exogenous, to the terminating network. The access mark-up is thus equal to:

$$
m \equiv a-c_{T}
$$


We will treat here the access charge as exogenous; later on, we study its impact on the equilibrium outcome.

Networks offer services that are horizontally differentiated à la Hotelling. Consumers are uniformly distributed on the segment $[0,1]$, and the two networks are located at the two ends of this segment. Consumers' tastes are represented by their location on the segment and taken into account through a "transport" cost $t>0$, reflecting their disutility from not enjoying their ideal type of service. For a given volume of calls $q$, a consumer joining a network located at a distance $x$ obtains a gross utility given by

$$
u(q)-t x
$$

where $u(q)$ denotes the variable gross surplus, with $u^{\prime}>0>u^{\prime \prime}$ and $u^{\prime}(0)=+\infty .^{7}$ Throughout the paper, we will assume that $u(0)$, the fixed surplus derived from being connected to either network, is large enough to ensure full participation. ${ }^{8}$ Finally, we assume that consumers switching to E's network incur a cost $s>0$.

Each network $i=E, I$ offers a three-part tariff $T_{i}=\left(F_{i}, p_{i}, \hat{p}_{i}\right)$, where $F_{i}$ is the subscription fee, and $p_{i}$ and $\hat{p}_{i}$ respectively denote on-net and off-net usage prices. Demand $q(p)$ is defined by $u^{\prime}(q(p))=p$ with $q>0$. Letting $\alpha_{i}$ denote network $i$ 's market share and assuming a balanced calling pattern, ${ }^{9}$ the net surplus offered by network $i$ is (for $i \neq j=I, E)$ :

$$
w_{i}=\alpha_{i} v\left(p_{i}\right)+\alpha_{j} v\left(\hat{p}_{i}\right)-F_{i},
$$

where

$$
v(p)=u(q(p))-p q(p)
$$

denotes the consumer surplus for a price $p$.

In the next sections we first characterize, for a given (reciprocal) access charge, the equilibrium of the competition game where networks simultaneously set their retail tariffs (subscription fees and usage prices), and consumers then choose a network and how much to call. We then study the impact of the access charge on this equilibrium.

\section{Shared-market equilibria}

In this Section we focus on shared-market equilibria - restricting attention to stable equilibria, achievable through a standard tâtonnement process. We first characterize usage

\footnotetext{
${ }^{7}$ This condition simplifies the exposition by ensuring that consumers always make calls. See footnote 19 for a discussion of its implications.

${ }^{8}$ This surplus may for example reflect the benefits from complementary services such as SMS, data services or the ability to receive calls for free (as is the case in most countries outside the U.S.), which are not explicitly modeled here.

${ }^{9}$ This assumption implies that, for equal prices, calls terminate on the two networks in proportion to their respective customer bases.
} 
prices, before discussing network externalities and market shares; we then characterize the condition under which a shared-market equilibrium exists, and show that it is then unique.

Marginal-cost pricing. Network $i$ 's profit is equal to:

$$
\pi_{i} \equiv \alpha_{i}\left[\alpha_{i}\left(p_{i}-c\right) q\left(p_{i}\right)+\alpha_{j}\left(\hat{p}_{i}-c-m\right) q\left(\hat{p}_{i}\right)+F_{i}-f\right]+\alpha_{i} \alpha_{j} m q\left(\hat{p}_{j}\right) .
$$

As usual, as the operators can use the fixed fees to share the surplus, they have an incentive to maximize this surplus by setting prices reflecting (perceived) marginal costs, equal to the true cost $c$ for on-net calls and augmented by the access mark-up $m$ for off-net calls:

Lemma 1 In any shared-market equilibrium, usage prices are equal to marginal costs:

$$
p_{i}^{S}=c, \hat{p}_{i}^{S}=c+m
$$

\section{Proof. See Appendix A.}

As a result, even though each network $i$ pays $\alpha_{i} \alpha_{j} m q\left(\hat{p}_{i}^{S}\right)$ to its rival, there is no net interconnection payment; as both networks charge the same off-net price $\left(\hat{p}_{i}^{S}=\hat{p}_{j}^{S}\right)$, neither the incumbent nor the entrant has a net outflow of calls: $\alpha_{i} \alpha_{j} m\left(q\left(\hat{p}_{j}^{S}\right)-q\left(\hat{p}_{i}^{S}\right)\right)=$ 0 , whatever networks' market shares.

Network Externalities and consumers' response. As the off-net price increases with the access mark-up, departing from cost-based access charges generates tariff-mediated network externalities. For example, if the access mark-up is positive, prices are higher for off-net calls $(c+m>c)$ and the subscribers of a network are thus better off, the more customers join that network. As usual with network effects, different expectations may yield different - even multiple - consumer responses. We will assume that, given networks' prices, consumers have self-fulfilling expectations; market shares thus constitute a fixed point of the "reaction to anticipations." 10 And to ensure that this consumer response is unique, we will assume that tariff-mediated network externalities are not too large, compared with consumers' relative taste for the two networks: ${ }^{11}$

$$
t>v(c)-v(\infty)
$$

The following Lemma characterizes this unique consumer response:

\footnotetext{
${ }^{10}$ We thus assume here that expectations respond to pricing deviations. Hurkens and López (2014) consider instead the case of passive self-fulfilling equilibrium expectations, that do not respond to deviations. They find that this attenuates the so-called waterbed effect (the extent to which higher termination revenues are passed on to consumers through lower subscription fees), and even annuls it in case of duopoly.

${ }^{11}$ This condition corresponds to the stability condition introduced in Laffont, Rey and Tirole (1998b, p. 52), and ensures that a small increase in the market share of a network cannot trigger a snowballing process towards that network.
} 
Lemma 2 In any shared-market outcome, consumers' response to networks' prices is given by:

$$
\alpha_{I}\left(F_{I}, F_{E}\right)=1-\alpha_{E}\left(F_{I}, F_{E}\right)=\frac{1}{2}+\frac{F_{E}-F_{I}+s}{2 \tau(m)}
$$

where

$$
\tau(m) \equiv t-[v(c)-v(c+m)]>0
$$

Proof. See Appendix B.

As usual, network $i$ 's market share decreases with its own price and increases with the rival's price, and all the more so when networks are close substitutes (i.e., $t$ is small). Incumbency moreover confers an advantage to $I$, as consumers must incur the switching $\operatorname{cost} s$ if they subscribe to $E$; hence, for equal prices, $I$ attracts a larger market share than its rival, and all the more so when the switching cost is large. In addition, pricemediated network externalities also affect the sensitivity of market shares to networks' prices. For instance, for $m>0$ consumers favour large networks (as off-net usage prices then exceed on-net ones), which tends to exacerbate consumers' responses to a price differential: Offering a better price attracts more consumers, which in turns makes the network more attractive for additional consumers, and so on. Condition (1) rules out "tipping," but market shares do become more sensitive to prices as $m$ increases.

Subscription fees and market shares. We now complete the characterization of the equilibrium. Intuitively, we would expect the operators to share the market as long as the switching cost is not too large. The following Lemma confirms this intuition, and moreover shows that the equilibrium is then unique:

Lemma 3 A stable shared-market equilibrium exists if and only if

$$
s<\psi(m) \equiv 3 \tau(m)+2 m q(c+m)
$$

Conversely, when this condition holds, there exists a unique stable shared-market equilibrium, in which subscription fees and market shares are respectively equal to:

$$
\begin{aligned}
F_{i}^{S}(m) & =f+\tau(m)+\frac{\delta_{i} s}{\psi(m)}[\tau(m)+m q(c+m)] \\
\alpha_{I}^{S}(m) & =1-\alpha_{E}^{S}(m)=\frac{1}{2}\left(1+\frac{s}{\psi(m)}\right)
\end{aligned}
$$

Proof. See Appendix C.

Condition (3) shows that a (stable) shared-market equilibrium exists (in which case it is unique) when:

- Switching costs are not too large: Switching costs confer market power to the incumbent, who obtains a larger market share $\left(\alpha_{I}>1 / 2\right)$, which moreover increases with $s$. 
- The entrant is sufficiently differentiated from the incumbent: Consumers are more likely to stick to their favourite network in case of strong differentiation; as $\psi$ increases with the differentiation parameter $t$, the market is more likely to be shared when $t$ is large, and E's market share moreover increases with $t$. For example, for cost-based access charges $(m=0)$, the market is shared as long as $t>s / 3 .^{12}$

- Network effects are not too large: When the access charge lies above cost, network effects confer a comparative advantage to the larger operator; this reinforces the market power of the incumbent, which becomes more likely to corner the market. Indeed, $\psi(m)$ decreases as $m$ increases above cost:

$$
\psi^{\prime}(m)=-q(c+m)+2 m q^{\prime}(c+m)
$$

which is negative for $m \geq 0$.

The expression of the subscription fees given by (4) is also intuitive:

- As usual when total demand is inelastic, perceived costs are passed through to consumers: Any increase in the connection cost $f$ is fully borne by subscribers.

- The second term, $\tau(m)=t-[v(c)-v(c+m)]$, reflects the impact of product differentiation and network effects on competition. Product differentiation softens competition: Subscription fees increase with the product differentiation parameter $t$. By contrast, network effects tend to intensify competition when $m$ is positive: As off-net calls are then priced above on-net calls, consumers prefer to join larger networks, all else being equal; this, in turn, induces networks to bid more aggressively for marginal customers. This effect becomes larger as the termination rate increases, as this reduces the value of off-net calls, $v(c+m)$.

- Here, however, switching costs confer a comparative advantage to the incumbent, reflected in the third term: The incumbent network charges a higher price than the entrant, and all the more so when switching costs are large. This effect, too, becomes larger as the termination mark-up increases, at least as long as this raises the termination revenue, $m q(c+m) \cdot{ }^{13}$

\footnotetext{
${ }^{12}$ As mentioned earlier, the utility derived from being connected to either network is supposed to be large enough to ensure full participation. Under cost-based access charges, the marginal consumer' net utility is equal to:

$$
v(c)-F_{I}-t \alpha_{I}=v(c)-s-F_{E}-t \alpha_{E}=v(c)-f-\frac{3 t+s}{2} .
$$

Therefore, a sufficient condition for full participation is $v(c)>f+3 t$ : This indeed ensures that the marginal consumer obtains a positive net utility whenever a shared-market equilibrium exists, i.e., whenever $t>s / 3$.

${ }^{13}$ We have:

$$
\frac{d}{d m}\left[\frac{\tau(m)+m q(c+m)}{\psi(m)}\right]=\frac{\tau(m) \frac{d}{d m}[m q(c+m)]+m q^{2}(c+m)}{\psi^{2}(m)},
$$

which is positive when $\frac{d}{d m}[m q(c+m)]>0$ and $m \geq 0$.
} 
The incumbency advantage is also reflected in I's equilibrium market share, which increases with $s$, all the more so when the access charge raises further above cost (as $\psi(m)$ then decreases with $m-$ see $(6))$.

Impact of the access charge. We now examine the impact of the access charge on equilibrium profits.

Starting from cost-based termination rates $(m=0)$, increasing the access charge (i) increases the intensity of competition (as reflected in the term $\tau(m)$ in (4)) and (ii) confers a comparative advantage to the incumbent, whose market share increases at the expense of the entrant. It follows that the entrant would always favour below-cost access charges.

The same would apply to the "incumbent" in the absence of switching cost, as networks would then be symmetric. This result, first derived by Gans and King (2001), has been shown to hold for more than two networks (Calzada and Valletti, 2008) as well as in the presence of call externalities (Berger, 2005) or when subscription demand is elastic (Hurkens and Jeon, 2012).

The impact of the access charge on the profit of the incumbent is more nuanced in the presence of switching costs, as they provide a comparative advantage that also increases with the termination mark-up. Yet, the next proposition shows that, as long as the market remains shared, the incumbent operator still favours access charges below cost:

Proposition 1 In the range of access charges yielding a shared-market equilibrium:

- (i) Both networks' equilibrium profits are higher for a cost-based access charge $(m=0)$ than for any positive termination mark-up $(m>0)$.

- (ii) A small termination subsidy $(m<0)$ gives both networks even greater profits.

Proof. See Appendix D.

While this proposition appears to extend the previous results, it only applies to termination mark-ups that are small enough to yield a shared-market equilibrium. As we will see, a large network may actually favour more extreme termination mark-ups that allow them to corner the market and charge high prices.

Welfare analysis. As all consumers subscribe (full participation) and usage prices reflect perceived marginal costs, total welfare (net of switching and transport costs) is equal to:

$$
\begin{aligned}
W(m) \equiv & {\left[\left(\alpha_{I}^{S}(m)\right)^{2}+\left(\alpha_{E}^{S}(m)\right)^{2}\right] v(c)+2 \alpha_{I}^{S}(m) \alpha_{E}^{S}(m)[v(c+m)+m q(c+m)] } \\
& -f-\alpha_{E}^{S}(m) s-\int_{0}^{\alpha_{I}^{S}(m)} t x d x-\int_{\alpha_{I}^{S}(m)}^{1} t(1-x) d x .
\end{aligned}
$$


The first two terms reflect the social value of on-net and off-net calls, respectively, whereas the other terms account for connection, switching and transport costs. Increasing the access charge above cost degrades the social value of off-net calls (i.e., $v(c+m)+m q(c+m)$ decreases with $m$ for $m>0$ ) and expands the market share of the incumbent (i.e., $\alpha_{I}^{S}(m)$ increases with $m$ ).

When the access charge is cost-based $(m=0)$, there are no network effects and welfare is simply driven by switching cost and relative preference considerations. The "efficient" market share of the entrant would make the marginal consumer $x=\alpha_{I}$ indifferent between sticking to the incumbent or incurring the switching cost and turning to the entrant; that is, it should satisfy

$$
t \alpha_{I}^{e f f}=s+t\left(1-\alpha_{I}^{e f f}\right)
$$

or

$$
\alpha_{I}^{e f f}=\frac{1}{2}+\frac{s}{2 t} .
$$

However, as noted above in equilibrium the incumbent exploits its market power and charges a higher fee than the entrant, which gives the entrant a higher share: $\alpha_{E}^{S}(0)>$ $\alpha_{E}^{e f f}$. Furthermore, starting from $m=0$, a small change in $m$ only has a second-order effect on the social value of off-net calls, against a first-order reduction of the market share of the entrant. It follows that raising $m$ slightly above cost enhances total welfare.

For higher levels of the access charge, the social value of off-net calls becomes significantly deteriorated, which tends to reduce welfare. A redeeming virtue, however, is that increasing I's market share reduces the share of off-net calls. It is straightforward to show that this redeeming virtue actually ensures that reducing further $E$ 's market share keeps enhancing total welfare, a positive effect however counter-balanced by the distortion on the volume of off-net calls. Let $W^{S}(m)$ denote total welfare in the shared-market equilibrium, for $m$ satisfying (3) we have: ${ }^{14}$

$$
\frac{d W^{S}}{d m}(m)=\frac{s}{\psi(m)}[t+\tau(m)] \frac{d \alpha_{I}^{S}}{d m}+2 \alpha_{I}^{S}(m) \alpha_{E}^{S}(m) m q^{\prime}(c+m) .
$$

The first term is positive, confirming that, as the access charge increases above cost, the expansion of $I$ 's market share keeps enhancing total welfare - even when it becomes larger than $\alpha_{I}^{e f f}$; the second term is however negative, reflecting the downward distortion on off-net calls $\left(q^{\prime}(\cdot)<0\right)$. Note that this second term vanishes not only for $m=0$, but also for $\alpha_{E}^{S}=0$; it follows that total welfare increases with $m$ both when the termination is almost cost-based, as already noted, and when there is almost complete foreclosure (i.e., $s$ close to $\psi(m))$.

\footnotetext{
${ }^{14}$ See Appendix E.
} 


\section{Profitable foreclosure through high termination rates}

We now show that the incumbent operator can find it profitable to corner the market through high termination rates. ${ }^{15}$

Cornered market equilibria. From Proposition 3, as $m$ increases $E$ attracts fewer and fewer subscribers, and its market share vanishes when $m$ reaches the level given by (9), namely

$$
\hat{m}(s) \equiv \psi^{-1}(s)
$$

Intuitively, we would expect $I$ to corner the market when $m$ further increases. The following Proposition confirms this intuition and shows furthermore that $I$ 's equilibrium profit then increases with the access charge:

Proposition 2 When $m \geq \hat{m}(s)$, there exists an equilibrium in which I corners the market, and:

- Usage prices reflect (perceived) marginal costs: $p_{i}^{C}=c$ and $\hat{p}_{i}^{C}=c+m$ for $i=I, E$.

- Subscription fees are $F_{E}^{C}(m)=f-m q(c+m)$ and $F_{I}^{C}(m)=f+s-\tau(m)-$ $m q(c+m)$.

Proof. See Appendix F.

This result calls for two comments. First, the Proposition identifies an equilibrium, but other ones exist as well (in which $I$ still corners the market):

- As in classic asymmetric Bertrand competition games, there are equilibria with lower subscription fees: If $E$ charges a lower fee, $I$ must match it in order to keep cornering the market; conversely, if $I$ matches the price cut, $E$ is willing to maintain the lower fee, as it does not attract any subscriber anyway. These other equilibria however rely on weakly dominated strategies for $E$. By contrast, in the equilibrium characterized by the proposition, $E$ offers a subsidy, equal to $m q(c+m)$, but would break even if it attracted a subscriber: The subsidy corresponds to the termination revenue generated by the subscriber.

- In addition, for the sake of exposition we restrict attention to equilibria where all usage prices are cost-based, as was the case for shared-market equilibria. However, when $I$ corners the market, the reasoning underlying Lemma 1 only ensures that $I$ must price onnet calls at cost (i.e., I's equilibrium on-net price must be $p_{I}^{C}=c$ ); the other usage prices (namely, I's off-net price, $\hat{p}_{I}^{C}$, and $E$ 's prices, $p_{E}^{C}$ and $\hat{p}_{E}^{C}$ ), being "unused" in equilibrium,

\footnotetext{
${ }^{15}$ We restrict attention here to above-cost access charges (i.e., $m \geq 0$ ), as these have been the focus of the policy debate. It can be checked that the entrant can never corner the market in this range - see López and Rey (2012).
} 
need not reflect perceived costs. ${ }^{16}$ And indeed, there exist other equilibria, in which $I$ still corners the market but off-net prices are not equal to $c+m \cdot{ }^{17}$ However, the analysis of these additional equilibria is notationally more cumbersome, and does not materially affect the main qualitative insights.

Second, as $m$ increases above $\hat{m}$, network effects exacerbate $I$ 's comparative advantage to such an extent that $I$ can increase its subscription fee - even though $E$ 's subscription fee keeps decreasing as long as raising $m$ increases the termination revenue $m q(c+m)$. It follows that I's profit, given by

$$
\pi_{I}^{C}(m) \equiv F_{I}^{C}(m)-f=s-\tau(m)-m q(c+m)
$$

increases with the access charge $m$ for $m>\hat{m}$.

Impact of the access charge. It follows from the above analysis that, if

$$
s>\bar{s} \equiv \psi(0)=3 t
$$

$I$ corners the market even with cost-based access charges $(m=0)$; conversely, the market remains shared even with infinite access charges if ${ }^{18}$

$$
s<\underline{s} \equiv \psi(\infty)=3(t-\Delta)
$$

where

$$
\Delta \equiv v(c)-v(\infty)
$$

denotes the maximal scope for network effects (note that $\underline{s}>0$ under $(1)$ ). We now focus on the case $\underline{s}<s<\bar{s}$, where the incumbent can foreclose the market when and only when the access charge is sufficiently high. Foreclosing the market in this way is profitable for $I$ when the maximum profit that it can obtain, ${ }^{19}$

$$
\pi_{I}^{C}(\infty)=s-t+\Delta
$$

exceeds the profit that it could obtain by sharing the market for $m=0$, which is equal

\footnotetext{
${ }^{16}$ We thank a referee for pointing this out. The same applies to deviations: A deviation aiming at cornering the market need not involve a cost-based off-net price. Proposition 2 however characterizes a "true" equilibrium: It survives any deviation, even those with usage prices that are not cost-based.

${ }^{17}$ In particular, there exist cornered-market equilibria, based on higher off-net prices, for $m$ slightly below $\hat{m}$.

${ }^{18}$ For the sake of exposition, we assume here that the termination revenue $m q(c+m)$ vanishes as the termination charges goes to infinity (that is, usage demand is sufficiently elastic).

${ }^{19}$ When demand vanishes for high usage prices, i.e., when $q(c+m)=0$ for $m$ larger than some $\bar{m}$, then the cornered-market equilibria characterized by Proposition 2 exist only if $\hat{m}(s)<\bar{m}$, and the maximum profit from foreclosure becomes $\pi_{I}^{C}(\bar{m})$. In the same vein, if we relax the assumption (1) ensuring that consumers' response to prices is uniquely defined, then the above analysis applies as long as $\tau(m)>0$, which may put another upper bound on the admissible range for the termination mark-up.
} 
to

$$
\pi_{I}^{S}(0)=\frac{t}{2}\left(1+\frac{s}{3 t}\right)^{2}
$$

The above analysis and the comparison of these two profit levels yield:

Proposition 3 (i) When $s \geq \bar{s}$, I corners the market even under cost-based termination $(m=0)$, and any increase in the access charge above cost enhances I's profit.

(ii) When $s<\underline{s}$, raising the access charge above cost does not enable I to corner the market, and thus always reduces I's profit.

(iii) Finally, when $s \in[\underline{s}, \bar{s})$, raising the access charge sufficiently above cost (namely, $m \geq \hat{m}(s)$ ) enables I to corner the market, and any further increase in $m$ increases I's profit; furthermore, when $s>\hat{s}$, where

$$
\hat{s} \equiv\left(2-\sqrt{1+2 \frac{\Delta}{t}}\right) 3 t
$$

lies between $\underline{s}$ and $\bar{s}$, foreclosing the market in this way is profitable for I, for a large enough access charge.

Proof. See Appendix G.

That the incumbent can corner the market when the switching cost is large enough is intuitive. More interestingly, even when it could not do so under cost-based termination (i.e., when $s<\bar{s}$ ), raising the access charge can enable the incumbent to foreclose the entrant, and this can be profitable when the switching cost is significant: When $\hat{s}<s<\bar{s}$, $I$ and $E$ would share the market for $m=0$, whereas $I$ corners the market for $m \geq \hat{m}(s)$, and obtains in this way a higher profit than for $m=0$ when $m$ is large enough. The analysis furthermore shows that this is more likely to happen when the networks are not too differentiated and/or networks effects are substantial (it can indeed be checked that $\hat{s}$ increases with $t$ and instead decreases as $\Delta$ increases).

Finally, note that $s>\hat{s}$ amounts to

$$
\alpha_{I}^{S}(0)=\frac{1}{2}\left(1+\frac{s}{3 t}\right)>\frac{1}{2}\left(3-\sqrt{1+2 \frac{\Delta}{t}}\right)
$$

where the right-hand side lies above $\frac{3-\sqrt{3}}{2} \simeq 63 \%$ as long as $\Delta<t$. Therefore, for foreclosure to be profitable, $I$ should keep at least about two-thirds of the market under cost-based access charges.

Welfare analysis. In the range $m \geq \hat{m}(s)$, where $I$ corners the market, total welfare remains constant: No consumer incurs the switching cost, total transport cost remains equal to $\int_{0}^{1} t x d x$, and all calls (being on-net) are priced at cost $(p=c)$; hence, total 
welfare is equal to

$$
W^{C}=v(c)-\int_{0}^{1} t x d x-f
$$

and thus remains constant as $m$ increases: $I$ simply appropriates a larger share of this surplus, at the expense of consumers, who face an increase in the subscription fee $F_{I}^{C}$.

To be sure, this welfare analysis is mainly relevant in the "short-term", as it assumes that the entrant keeps exerting a competitive pressure even when its market share vanishes. A more complete analysis should take into consideration the risk of exit (but would also need to account for the operators' incentives to price strategically, so as to build customer bases).

\section{Illustration}

In this section we illustrate the analysis using a constant-elasticity demand of the form $q(p)=d p^{-\varepsilon}$, where $d>0$ and $\varepsilon>1 ;^{20}$ the consumer surplus is then given by

$$
v(p)=v_{0}+d \frac{p^{1-\varepsilon}}{\varepsilon-1}
$$

where $v_{0}$ is supposed to be large enough to ensure full participation.

For illustrative purposes, we adopt the following parameter values: $\varepsilon=1.6, c_{T}=0.5$, $c=c_{O}+c_{T}=2, f=0, d=5, t=6$ and $s=10$. Condition (1) is thus satisfied, as $t=6>\Delta \simeq 5.5$, and the feasible range for the access mark-up is $m \geq-c_{T}=-0.5$. In addition, $\bar{s}=18>s>\hat{s} \simeq 5.7(>\underline{s} \simeq 1.5)$.

Figure 1 represents the equilibrium market shares as a function of the access charge. As $s<\bar{s}, E$ gains some market share under cost-based termination: $\alpha_{E}^{S}(0)=2 / 9 \simeq 22 \%$; this market share decreases with $m$ in the range where the market is shared. Furthermore,

\footnotetext{
${ }^{20}$ This condition ensures that the termination revenue, $m q(c+m)$, vanishes as $m$ goes to infinity.
} 
as $s>\underline{s}, I$ forecloses the market when the access charge exceeds $\hat{m}(s) \simeq 7.5$.

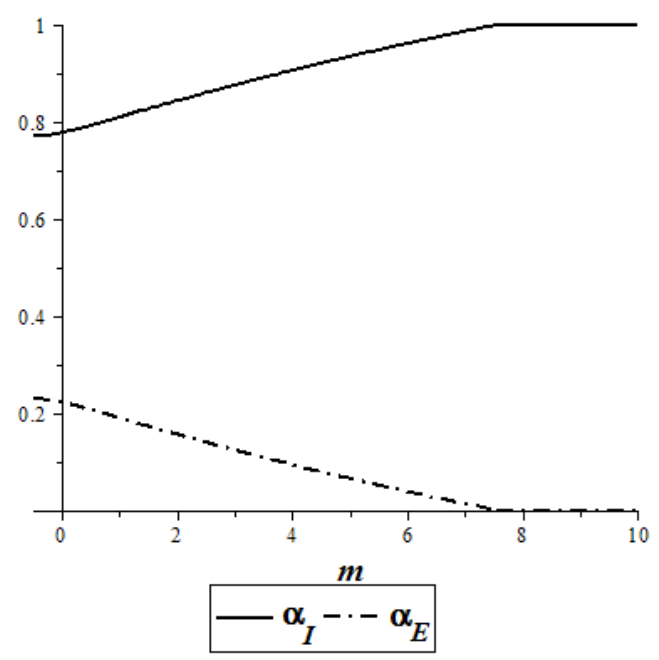

Figure 1. Equilibrium market shares.

Figure 2 represents the impact of the access charge on I's equilibrium profit:

- In the range $m<\hat{m}(s) \simeq 7.5$ (including in the limited admissible range of negative values for $m$ ), where the two networks share the market, both operators' profits decrease as $m$ increases; "bill and keep" (that is, no access charge: $a=0$, or $\left.m=-c_{T}=-0.5\right)$ thus constitutes the most profitable reciprocal access agreement in this range.

- In the range $m \geq \hat{m}(s), I$ corners the market by charging $F_{I}=f+s-\tau(m)-$ $m q(c+m) ; E$ thus obtains no profit, whereas $I$ 's profit increases with $m$ (as this reduces the competitive pressure exerted by the entrant operator, and allows the incumbent operator to charge a higher subscription fee), to such an extent that it becomes higher than in any shared-market equilibrium (even with "bill and keep") when $m$ is large enough (namely, when $m>22$ ). Therefore, $I$ will prefer to corner the market with a large enough access mark-up rather than sharing the market with lower or below-cost access charges. 


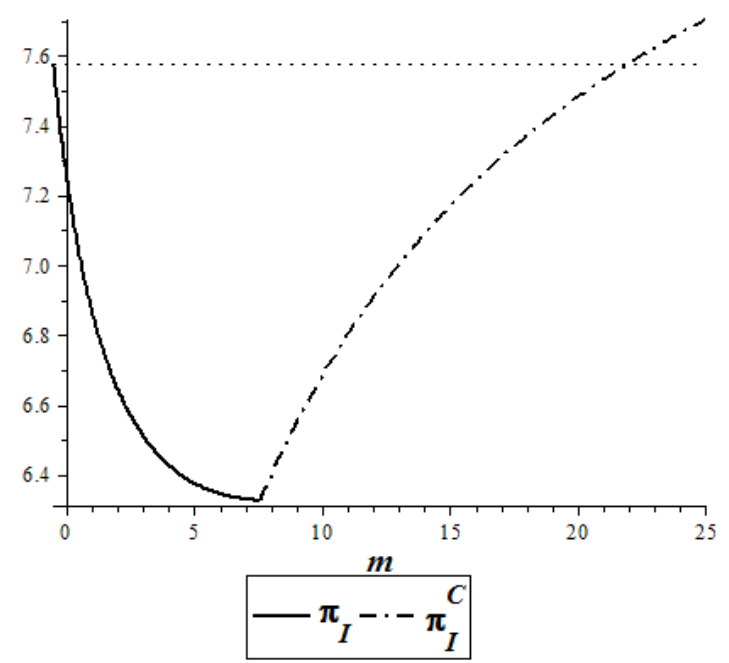

Figure 2.a. I's profit.

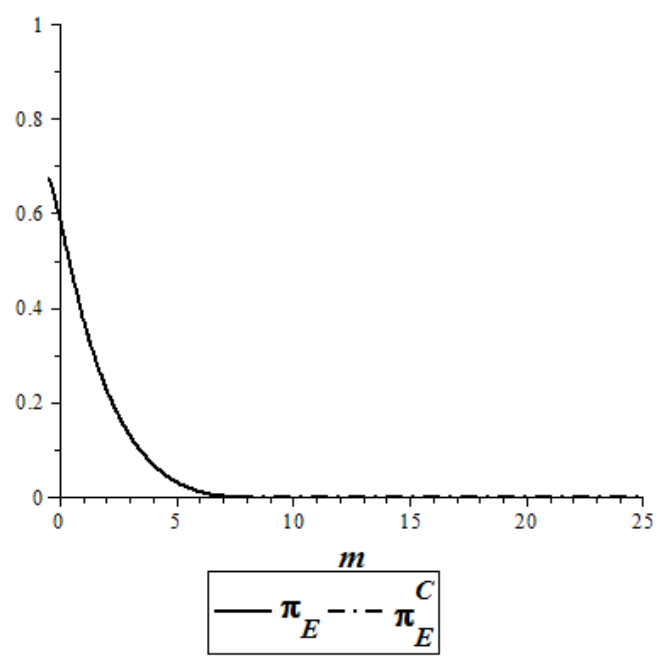

Figure 2.b. E's profit.

Next, we consider the impact of the access charge on total welfare $(W)$, which is given by (7), and on consumer surplus $(C S)$, net of subscription fees as well as switching and transport costs, which is given by:

$$
\begin{aligned}
C S= & \left(\alpha_{I}^{2}+\alpha_{E}^{2}\right) v(c)+2 \alpha_{I} \alpha_{E} v(c+m)-\alpha_{I} F_{I}-\alpha_{E} F_{E} \\
& -\alpha_{E} s-\int_{0}^{\alpha_{I}} t x d x-\int_{\alpha_{I}}^{1} t(1-x) d x .
\end{aligned}
$$

Figure 3a presents the impact of the access charge on total welfare, $W$, in the range $m<\hat{m}(s)$, and remains constant afterwards. Interestingly, in this example total welfare always increases with $m$ as long as the networks share the market. As both profits decrease in $m$ as long as the market remains shared, and $I$ 's profit increases with $m$ when it corners the market, it follows that, as illustrated by Figure 3b, consumer surplus (which can be expressed as total welfare minus industry profit) first increases with $m$ as long as $m<\hat{m}(s)$, and decreases afterwards - for a sufficiently high access charge, it may even lie below the level achieved for $m=0$. 


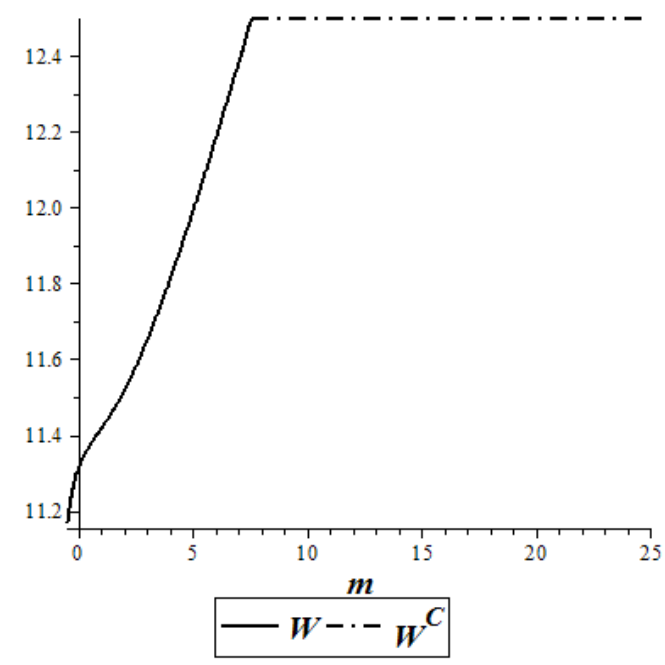

Figure 3.a. Total Welfare.

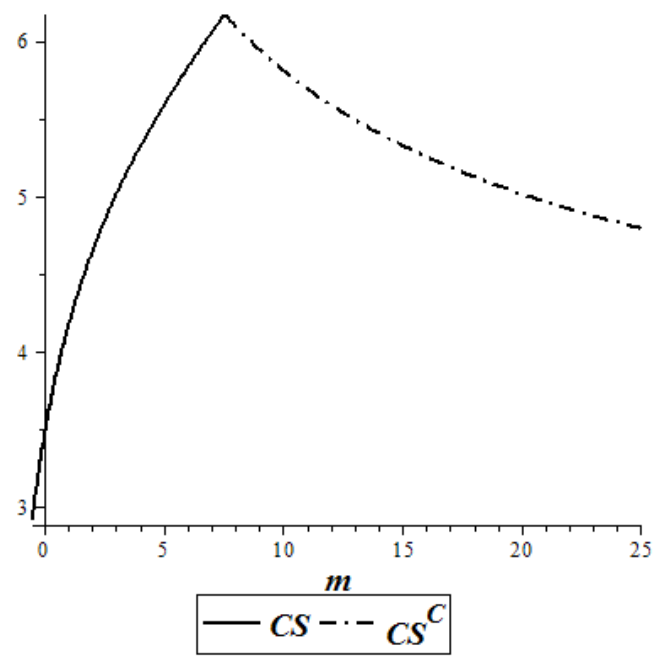

Figure 3.b. Consumer Surplus.

\section{The role of termination-based price discrimination}

We now stress that on-net pricing is key to profitable foreclosure. More precisely, we first show that foreclosure is never profitable in the absence of termination-based price discrimination, and then note that it would not even be feasible if in addition networks were adopting the so-called "receiver-pays" regime, in which network operators also charge users for receiving calls.

\section{Caller-pays regime}

We consider here the same setup as before, except that networks cannot charge different prices for off-net and on-net calls; that is: $\hat{p}_{i}=p_{i}$ for $i=I, E$ :

$$
\pi_{i} \equiv \alpha_{i}\left[\left(p_{i}-c\right) q\left(p_{i}\right)+F_{i}-f\right]+\alpha_{i} \alpha_{j} m\left(q\left(p_{j}\right)-q\left(p_{i}\right)\right)
$$

The same argument as in Lemma 1 then yields again cost-based usage pricing in any shared-market equilibrium, namely:

$$
p_{i}=c+\alpha_{j} m
$$

Under a cost-based access charge (i.e., $m=0$ ), networks price calls at cost $\left(p_{i}=c\right)$ and the equilibrium is thus the same as before. The next Proposition shows that it is never profitable for the incumbent to raise the access charge so as to corner the market: 
Proposition 4 In the absence of the termination-based price discrimination:

(i) When $s \geq \bar{s}=3 t, I$ corners the market even under cost-based termination $(m=0)$; raising the access charge above cost then reduces I's equilibrium profit.

(ii) When instead $s<\bar{s}$, raising the access charge above cost is never profitable for I, even if it enables it to foreclose the market.

\section{Proof. See Appendix H.}

The intuition is simple, and comes from the fact that increasing the access charge tends to make the entrant more aggressive. As noted by the literature (see, e.g., Carter and Wright (2003) ${ }^{21}$ and López (2008)), increasing the access charge induces both network operators to raise their usage prices, and even more so for the entrant (because it has a higher proportion of off-net calls); this, in turn, creates an access revenue for the entrant, which then competes more aggressively for subscribers through a lower fee. This effect is most easily seen when the access charge already enables $I$ to corner the market. In this case:

- Attracting a consumer with a fee $F_{E}$, together with a usage price reflecting the perceived cost of off-net calls, would give $E$ a profit equal to $F_{E}-f+m q(c)$, where the last term represents the termination revenue that $E$ would earn from $I$ 's incoming calls; therefore, $E$ is willing to offer any fee (together with $p_{E}=c+m$ ) down to

$$
F_{E}=f-m q(c)
$$

- To corner the market, $I$ must offer a net surplus $w_{I}$ matching $w_{E}+t-s$; to be sure, the higher usage price charged by $E$ allows $I$ to maintain a fee differential: more precisely, it can offer $w_{I}=w_{E}+t-s$ by charging ${ }^{22}$

$$
\begin{aligned}
F_{I} & =F_{E}+s-t+v(c)-v(c+m) \\
& =F_{E}+s-\tau(m) .
\end{aligned}
$$

The expression in (11) confirms that an increase in the access charge makes the entrant more aggressive, by increasing the termination revenue $m q(c)$ attached to any new subscriber. The expression in (12) shows that this effect is partially compensated by the fee differential, as reflected in the term $v(c)-v(c+m)$, that $I$ can afford given $E$ 's higher usage price. Yet an increase in $m$ increases the termination revenue $m q(c)$ more

\footnotetext{
${ }^{21}$ To capture brand loyalty, Carter and Wright (2003) introduce a parameter $\beta$, representing the extra benefits from belonging to the incumbent network: A consumer joining $I$ 's network located at a distance $x$ obtains a gross utility given by $u(q)-t x+\beta t$. The parameter $\beta$ thus plays the same role as a switching cost $s=\beta t$.

${ }^{22}$ Indeed, $s \geq \bar{s}=3 t$ and $m>0$ together imply $F_{I}>F_{E}$.
} 
than it does to the fee differential $v(c)-v(c+m),{ }^{23}$ and as a result I's equilibrium profit is reduced.

\section{Receiver-pays regime}

In most European countries mobile operators do not charge subscribers for receiving calls, even if this is not explicitly forbidden by NRAs. In contrast, in the United States mobile network operators usually charge subscribers for the calls they receive. Jeon, Laffont and Tirole (2004) and López (2011) ${ }^{24}$ show that, when networks compete in three-part tariffs of the form $\left\{F_{i}, p_{i}, r_{i}\right\}$, where $r_{i}$ denotes a per-unit reception charge, then in equilibrium they charge call origination and call reception at the off-net $\operatorname{cost}^{25}$ :

$$
p_{i}=c+m, \quad r_{i}=-m .
$$

Moreover, when setting usage prices at the off-net cost, $i$ 's profit writes as $\hat{\pi}_{i}=\alpha_{i}\left(F_{i}, F_{j}\right)\left(F_{i}-f\right)$, which does not depend on $m$. In other words, $m$ affects usage prices but not the intensity of competition in subscription fees. As a result, the access charge has no impact on equilibrium profits. Therefore, in the absence of on-net pricing, networks cannot use access charges to soften or foreclose competition when they charge for incoming calls.

\section{Conclusion}

We have examined the impact of reciprocal access charges on entry when consumers face switching costs, and networks compete in three-part tariffs, charging possibly different prices for off-net calls. The analysis shows that when switching costs are sufficiently large, high (reciprocal) access charges allow the incumbent to foreclose the market and exploit fully the resulting monopoly power.

Foreclosure strategies are profitable here only when they result in complete entry deterrence: While the incumbent can increase its market share by insisting on abovecost reciprocal charges, as long as the entrant keeps attracting some subscribers, raising

\footnotetext{
${ }^{23}$ Indeed, for $m>0$ :
}

$$
\frac{d}{d m}(v(c)-v(c+m)-m q(c))=q(c+m)-q(c)<0 .
$$

\footnotetext{
${ }^{24}$ López (2011) generalizes the framework of Jeon, Laffont and Tirole (2004) by allowing a random (non-vanishing) noise in both the callers' and receivers' utilities, by removing the assumption of a given proportionality between the utility functions, and by allowing asymmetry between firms with respect to the installed customer bases.

${ }^{25}$ López (2011) show that this equilibrium exists and is unique even if the random noise of the utilities does not vanish, and thereby receivers can hang up. Cambini and Valletti (2008), and Jeon, Laffont and Tirole (2004), however, consider the case of vanishing noise, where the caller determines the volume of calls 'most of the time'.
} 
the termination charge intensifies price competition and, as a result, both operators' equilibrium profits are lower than when the reciprocal access charge is at or below cost. In other words, limiting entry without deterring it entirely is never profitable.

Finally, the network effects created by termination-based price discrimination appear to be a key ingredient for profitable foreclosure strategies: In the absence of on-net pricing, the incumbent does not find it profitable to foreclose competition through high access charges. In addition, in a receiver-pays regime, the incumbent operator cannot use the access charge to foreclose competition.

The policy implications of this analysis support a call for regulatory intervention in markets where an incumbent faces potential competition from a new entrant. This regulatory intervention could take the form of a cap on the reciprocal termination charge, and possibly a lower cap for access to the incumbent network (asymmetric regulation). Setting these caps would however require detailed knowledge of cost and demand competition; an alternative, possibly softer and more easily enforceable form of regulatory intervention would be to ban termination-based price discrimination - or to move towards a receiver-pays regime.

To refine these policy implications, further research can extend the analysis in at least two directions. First, it would be interesting to allow for the arrival of new customers, unattached to the incumbent network. Cornering its customer base would however make the incumbent network more attractive to these new customers as well. Hence, when there are relatively few new customers, the incumbent operator should still be able to foreclose the entrant when access charges are high enough. However, complete foreclosure is likely to become more difficult, and probably less profitable, as the proportion of new customers increases. Exploring further the possibility and profitability of such foreclosure, as a function of the proportion of new consumers, would contribute to identify the situations in which foreclosure may be a serious concern.

Second, our model features only one incumbent and one entrant. While the analysis readily extends to the case of multiple entrants, it would be useful to consider as well the case of tight incumbent oligopolies. The incumbent operators may then face a tradeoff between softening competition among themselves, and fighting the entrant(s). The literature however shows that the impact of access charges on the competition between incumbents depends critically on several factors, such as the type of tariffs, demand heterogeneity and arbitrage possibilities. For instance, Laffont, Rey and Tirole (1998a) show that while raising the access charge above cost yields higher usage prices, it can also trigger more intense competition for subscribers (as they bring termination revenues) when networks compete in other dimensions. Hence, while incumbent operators favor high access charges when they simply compete in (uniform) linear prices, in the case of two-part tariffs, for instance, this "waterbed effect" 26 can induce networks to reduce their fixed

\footnotetext{
${ }^{26}$ The term "waterbed effect" was first coined by Prof. Paul Geroski during the investigation of the
} 
fees, up to the point that the termination charge no longer affects equilibrium profits. López (2008) however points out that, in a dynamic setting, networks can still use (future) reciprocal access charges to soften competition. ${ }^{27}$ By contrast, as discussed above, termination-based price discrimination (i.e., on-net pricing) generates network effects which further intensify competition for subscribers, and as a result incumbent operators would rather favor termination charges that are below cost. However, as stressed by Armstrong and Wright (2009), the possibility of arbitrage between (high) fixed-to-mobile (FTM) and (low) mobile-to-mobile (MTM) charges ${ }^{28}$ may still induce mobile operators to favor high termination charges. ${ }^{29}$ Jullien, Rey and Sand-Zantman (2013), Hoernig, Inderst and Valletti (2014), Hurkens and López (2014), and Tangerås (2014) provide alternative explanations for why firms may prefer above-cost access charges, based respectively on demand heterogeneity, unbalanced calling patterns, alternative forms of consumer expectations, and income effects. Our analysis suggests that foreclosure may provide one additional motive for doing so.

\section{Appendix}

\section{A Proof of Lemma 1}

Adjusting $F_{i}$ so as to maintain net surpluses $w_{I}$ and $w_{E}$ - and thus market shares constant, network $i$ 's optimal prices $p_{i}$ and $\hat{p}_{i}$ maximize

$$
\alpha_{i}\left\{\alpha_{i}\left[\left(p_{i}-c\right) q\left(p_{i}\right)+v\left(p_{i}\right)\right]+\alpha_{j}\left[\left(\hat{p}_{i}-c-m\right) q\left(\hat{p}_{i}\right)+v\left(\hat{p}_{i}\right)\right]-w_{i}-f\right\}+\alpha_{i} \alpha_{j} m q\left(\hat{p}_{j}\right),
$$

which yields marginal-cost pricing.

\section{B Proof of Lemma 2}

If consumers anticipate market shares $\bar{\alpha}_{I}$ and $\bar{\alpha}_{E}=1-\bar{\alpha}_{I}$, they expect a net surplus

$$
w_{i}=\bar{\alpha}_{i} v(c)+\bar{\alpha}_{j} v(c+m)-F_{i}
$$

impact of fixed-to-mobile termination charges on retail prices. See also Genakos and Valletti (2011).

${ }^{27}$ Departing from cost-based termination charges adversely affects larger networks, which in turn reduces networks' incentives to build market shares.

${ }^{28}$ Historically, fixed and mobile operators were not really competing against each other, and thus a traditional "one-way access" analysis applied. Termination charges between those two types of networks are moreover usually asymmetric, different termination costs and regulatory constraints leading to relatively low charges for mobile-to-fixed calls and substantially higher charges for fixed-to-mobile calls.

${ }^{29}$ If mobile operators must adopt the same termination charge for FTM and MTM calls, this uniform charge may then be above cost if the waterbed effect on FTM is limited or if operators set their own charges unilaterally. 
from joining network $i$, for $i \neq j=I, E$. A consumer located at a distance $x \in[0,1]$ from network $I$ is therefore willing to stay with that network when $w_{I}-t x \geq w_{E}-$ $t(1-x)-s$, and prefers to switch otherwise. In a shared-market outcome, the actual consumer response, $\hat{\alpha}_{i}$, as a function of consumers' expectation $\bar{\alpha}_{i}$, is therefore given by $\max \left\{\min \left\{\hat{\alpha}_{i}\left(\bar{\alpha}_{i}\right), 1\right\}, 0\right\}$, where:

$$
\begin{aligned}
\hat{\alpha}_{i}\left(\bar{\alpha}_{i}\right) & =\frac{1}{2}+\frac{w_{i}-w_{j}+\delta_{i} s}{2 t} \\
& =\frac{1}{2}+\frac{F_{j}-F_{i}+\delta_{i} s}{2 t}+\frac{v(c)-v(c+m)}{t}\left(\bar{\alpha}_{i}-\frac{1}{2}\right),
\end{aligned}
$$

with $\delta_{I}=1$ and $\delta_{E}=-1$.

Condition (1) implies that the slope $d \hat{\alpha}_{i} / d \bar{\alpha}_{i}$ is lower than 1 , or

$$
\tau(m)=t-[v(c)-v(c+m)]>0
$$

Indeed, as $\tau^{\prime}(m)=-q(c+m)<0$, it follows that $\tau(m)>\tau(+\infty)$, which is positive under (1). This, in turn, ensures that consumers' response to subscription fees is always unique (and stable). When the market is shared, network $i$ 's market share corresponds to the fixed point $\bar{\alpha}_{i}=\hat{\alpha}_{i}\left(\bar{\alpha}_{i}\right)$, which leads to $(2)$.

\section{Proof of Proposition 3}

As already noted in the proof of Lemma 2, condition (1) implies $\tau(m)>0$. From Lemma 1 , in any shared-market equilibrium networks charge (perceived) cost-based usage prices: $p^{S}=c$ and $\hat{p}^{S}=c+m$. The same reasoning applies to small deviations: As long as the market remains shared, without loss of generality we can restrict attention to deviations that involve cost-based usage pricing. Following such a deviation, network $i$ 's profit can be written as (for $i \neq j=I, E)$ :

$$
\pi_{i}=\alpha_{i}\left(F_{I}, F_{E}\right)\left[F_{i}-f+\alpha_{j}\left(F_{I}, F_{E}\right) m q(c+m)\right]
$$

The first-order and second-order derivatives of this profit with respect to network $i$ 's subscription fee $F_{i}$ are respectively equal to:

$$
\begin{aligned}
\frac{\partial \pi_{i}}{\partial F_{i}} & =-\frac{F_{i}-f+\alpha_{j}\left(F_{I}, F_{E}\right) m q(c+m)}{2 \tau(m)}+\alpha_{i}\left(F_{I}, F_{E}\right)\left[1+\frac{m q(c+m)}{2 \tau(m)}\right] \\
& =-\frac{\varphi(m) F_{i}-[\tau(m)+m q(c+m)]\left(F_{j}+\delta_{i} s\right)-\tau(m)[f+\tau(m)]}{2 \tau^{2}(m)} \\
\frac{\partial^{2} \pi_{i}}{\partial F_{i}^{2}} & =-\frac{\varphi(m)}{2 \tau^{2}(m)} .
\end{aligned}
$$


where

$$
\varphi(m)=2 \tau(m)+m q(c+m) .
$$

In a shared-market equilibrium, the first-order conditions

$$
\frac{\partial \pi_{i}}{\partial F_{i}}=0
$$

must be satisfied for $i=I, E$, as well as the second-order conditions, which boil down to

$$
\varphi(m) \geq 0
$$

Conversely, under (16) network $i$ 's profit $\pi_{i}$ is globally concave; the local conditions (15) thus rule out any deviations to shared-market outcomes, including the limit cases $\alpha_{i}=0$ and $\alpha_{i}=1$. This, in turn, rules out any larger deviation:

- Network $i$ cannot benefit from "pricing itself out," as this would yield the same profit (zero) as in the limit case $\alpha_{i}=0$.

- Any deviation in which network $i$ corners the market would involve lower margins than the limit case $\alpha_{i}=1$, without attracting any additional subscriber. To see this, it suffices to note that:

- Without loss of generality, we can restrict attention to deviations involving an onnet price equal to cost: $p=c$ (when deviating, it remains optimal to maximize the gains from trade)

- The deviating profit is thus simply equal to

$$
\pi_{i}=F_{i}-f
$$

which is of the form (14) for $\alpha_{i}\left(F_{I}, F_{E}\right)=1$.

- And in order to corner the market, $I$ must offer a subscription fee $F_{I}^{D}$ that is sufficiently attractive, namely, such that $w_{I}^{D} \geq t-s+w_{E}^{S}$, where $w_{E}^{S}$ denotes the surplus corresponding to $E$ 's equilibrium offer, when all other consumers subscribe to $I$ :

$$
w_{I}^{D}=v(c)-F_{I}^{D} \geq t-s+w_{E}^{D}=t-s+v(c+m)-F_{E}^{S}
$$

which implies that $F_{I}^{D}$ cannot exceed the level such that $\alpha_{I}\left(F_{I}^{D}, F_{E}^{S}\right)=1$.

The first-order condition (15) yields network $i$ 's best response to the rival fee $F_{j}$ : for $i \neq j \in\{I, E\}$,

$$
F_{i}=F_{i}^{r}\left(F_{j}\right) \equiv \frac{\tau(m)+m q(c+m)}{\varphi(m)}\left(F_{j}+\delta_{i} s\right)+\frac{\tau(m)}{\varphi(m)}[f+\tau(m)] .
$$


Combining the above best-responses yields the expressions (4) and (5) for the equilibrium subscription fees and market shares.

To be stable, the equilibrium must satisfy $\left|\partial F_{i}^{r} / \partial F_{j}\right|<1$. This, in turn, implies $\psi(m)>0$ :

- When $\tau(m)+m q(c+m) \geq 0,(16)$ implies that subscription fees are (weak) strategic complements $\left(\partial F_{i}^{r} / \partial F_{j} \geq 0\right)$, in which case consumer-response stability, i.e., condition (13), implies both (price) stability $\left(\partial F_{i}^{r} / \partial F_{j} \leq 1\right)$ and

$$
\psi(m)=2[\tau(m)+m q(c+m)]+\tau(m)>0 .
$$

- When instead $\tau(m)+m q(c+m)<0$, subscription fees are strategic substitutes $\left(\partial F_{i}^{r} / \partial F_{j}<0\right)$, in which case (price) stability requires:

$$
\begin{aligned}
1 & >-\frac{\partial F_{i}^{r}}{\partial F_{j}}=-\frac{\tau(m)+m q(c+m)}{2 \tau(m)+m q(c+m)} \\
\Leftrightarrow \quad \psi(m) & =3 \tau(m)+2 m q(c+m)>0 .
\end{aligned}
$$

Conversely, when $\psi(m)>0$ :

- The candidate equilibrium market shares defined by (5) satisfy $\alpha_{I}=1-\alpha_{E}>0$.

- These market shares also satisfy $\alpha_{I}=1-\alpha_{E}<1$ if and only if (3) holds.

Finally, together with (13), condition (3) implies:

$$
\varphi(m)=\frac{\tau(m)+\psi(m)}{2}>0 .
$$

Therefore, (3) is a necessary and sufficient condition for the existence of a stable, sharedmarket equilibrium. In addition, when this condition holds, the shared-market equilibrium is unique and characterized by the subscription fees and market shares given by (4) and $(5)$.

\section{Proof of Proposition 1}

Using (14), (4) and (5), network $i$ 's equilibrium profit can be written as, for $i \neq j \in\{I, E\}$ :

$$
\begin{aligned}
\pi_{i} & =\alpha_{i}^{S}\left[F_{i}^{S}-f+\alpha_{j}^{S} m q(c+m)\right] \\
& =\frac{1}{2}\left(1+\frac{\delta_{i} s}{\psi(m)}\right)\left[\tau(m)+\frac{\tau(m)+m q(c+m)}{\psi(m)} s+\frac{1}{2}\left(1-\frac{\delta_{i} s}{\psi(m)}\right) m q(c+m)\right] \\
& =\frac{\varphi(m)}{4}\left(1+\frac{\delta_{i} s}{\psi(m)}\right)^{2} .
\end{aligned}
$$

where $\varphi(m)=2 \tau(m)+m q(c+m)>0$.

It is straightforward to check that, for $m \geq 0$, both $\varphi$ and $\psi$ strictly decrease with $m$. 
It follows that $E$ 's profit decreases with $m$ when $m \geq 0$; by continuity, the same is true for $m$ slightly negative.

We now show that $I$ 's profit satisfies $\pi_{I}(m)<\pi_{I}(0)$ for any $m>0$. Since $\delta_{I}=1$ and $2 \psi(m)=3 \varphi(m)+m q(c+m)>3 \varphi(m)$ in the range $m>0$, we have:

$$
\pi_{I}(m)=\frac{\varphi(m)}{4}\left(1+\frac{s}{\psi(m)}\right)^{2}<\Psi(m) \equiv \frac{\psi(m)}{6}\left(1+\frac{s}{\psi(m)}\right)^{2},
$$

where

$$
\Psi^{\prime}(m)=\frac{d}{d \psi}\left[\frac{\psi}{6}\left(1+\frac{s}{\psi}\right)^{2}\right] \psi^{\prime}=\frac{1}{6}\left(1+\frac{s}{\psi}\right)\left(1-\frac{s}{\psi}\right) \psi^{\prime}=\frac{2}{3} \alpha_{I}^{S}\left(1-\alpha_{I}^{S}\right) \psi^{\prime}<0
$$

As $\psi^{\prime}(m)<0$ and $\alpha_{I}^{S} \in(0,1)$ in the relevant range, it follows that $\Psi^{\prime}(m)<0 . \Psi(0)=$ $\pi_{I}(0)$, for $m>0$ we have:

$$
\pi_{I}(m)<\Psi(m)<\Psi(0)=\pi_{I}(0) .
$$

Similarly, for $m<0$ we have $2 \psi(m)<3 \varphi(m)$ and thus:

$$
\pi_{I}(m)>\Psi(m)
$$

As $\Psi(0)=\pi_{I}(0)$ and $\Psi^{\prime}(0)<0, \pi_{I}(m)>\pi_{I}(0)$ for $m$ slightly negative.

\section{E Welfare}

Taking the derivative of the expression of total welfare given by (7), we have:

$$
\begin{aligned}
\frac{d W^{S}}{d m}(m)= & \left\{2\left[\alpha_{I}^{S}(m)-\alpha_{E}^{S}(m)\right] v(c)+2\left[\alpha_{E}^{S}(m)-\alpha_{I}^{S}(m)\right][v(c+m)+m q(c+m)]\right. \\
& \left.+s-t \alpha_{I}^{S}(m)+t \alpha_{E}^{S}(m)\right\} \frac{d \alpha_{I}^{S}}{d m}(m)+2 \alpha_{I}^{S}(m) \alpha_{E}^{S}(m) m q^{\prime}(c+m) \\
= & \left\{s-\left[2 \alpha_{I}^{S}(m)-1\right][t-2 v(c)+2 v(c+m)+2 m q(c+m)]\right\} \frac{d \alpha_{I}^{S}}{d m}(m) \\
& +2 \alpha_{I}^{S}(m) \alpha_{E}^{S}(m) m q^{\prime}(c+m),
\end{aligned}
$$


which, using the expression of the market shares given by (4), and noting that the second term within square brackets can be expressed as $2 \tau(m)-t+2 m q(c+m)$, boils down to:

$$
\begin{aligned}
\frac{d W^{S}}{d m}(m)= & \left\{s-\frac{2 s}{\psi(m)}[2 \tau(m)-t+2 m q(c+m)]\right\} \frac{d \alpha_{I}^{S}}{d m}(m)+2 \alpha_{I}^{S}(m) \alpha_{E}^{S}(m) m q^{\prime}(c+m) \\
= & \frac{s}{\psi(m)}\{3 \tau(m)+2 m q(c+m)-[2 \tau(m)-t+2 m q(c+m)]\} \frac{d \alpha_{I}^{S}}{d m}(m) \\
& +2 \alpha_{I}^{S}(m) \alpha_{E}^{S}(m) m q^{\prime}(c+m) \\
= & \frac{s}{\psi(m)}[t+\tau(m)] \frac{d \alpha_{I}^{S}}{d m}(m)+2 \alpha_{I}^{S}(m) \alpha_{E}^{S}(m) m q^{\prime}(c+m) .
\end{aligned}
$$

\section{F Proof of Proposition 2}

For the sake of exposition, we restrict attention to equilibria in which networks still set usage prices at perceived marginal costs. In such a candidate equilibrium, consumers located at the other end of the segment must prefer to stick to I's network: $v(c)-t-F_{I} \geq$ $v(c+m)-s-F_{E}$. Furthermore, if this inequality holds strictly then $I$ could increase its subscription fee and still corner the market. Therefore, the inequality must be binding, which amounts to:

$$
F_{I}=F_{E}-\tau(m)+s
$$

In addition, $E$ should not be able to make a profit by attracting some consumers, and conversely $I$ should not gain from increasing its fee at the expense of market share. In the light of the previous analysis, it suffices to consider local deviations:

Lemma 4 Consider a candidate equilibrium in which I corners the market with costbased usage prices and subscription fees satisfying (18). The first-order conditions

$$
\frac{\partial \pi_{I}}{\partial F_{I}} \leq 0, \frac{\partial \pi_{E}}{\partial F_{E}} \geq 0
$$

where the profits $\pi_{I}$ and $\pi_{E}$ are given by (14), provide necessary and sufficient conditions for the existence of such an equilibrium.

Proof. Consider first deviations inducing a shared-market outcome, in which case without loss of generality we can restrict attention to deviant offers based on cost-based usage prices; the associated profit is thus given by (14). Furthermore, for $m \geq 0$ condition (13) ensures that this profit is strictly concave (i.e., $\varphi(m)>0$ ). Therefore, the first-order conditions (19) provide necessary and sufficient conditions for this kind of deviations. The condition for $I$ furthermore ensures that $I$ makes a profit (as it is not be profitable for $I$ to price itself out of the market, so as to induce $\left.\alpha_{I}\left(F_{I}^{D}, F_{E}\right)=0\right)$.

The same reasoning as in Appendix C can then be used to rule out "larger" deviations inducing a cornered-market outcome: No network $i$ can benefit from "pricing itself out," 
and conversely any deviation aiming at cornering the market would involve lower margins than the boundary case $\alpha_{i}=1$, without attracting any additional subscriber.

The first-order condition for $E$ amounts to say that it should not be able to make a profit by attracting its closest consumers, namely:

$$
F_{E} \leq f-m q(c+m)
$$

Conversely, I should not gain from a marginal increase in its fee:

$$
\begin{aligned}
0 \geq\left.\frac{\partial \pi_{I}}{\partial F_{I}}\right|_{\alpha_{I}=1} & =-\frac{F_{I}-f}{2 \tau(m)}+1+\frac{m q(c+m)}{2 \tau(m)} \\
& =-\frac{1}{2 \tau(m)}\left[F_{I}-f-2 \tau(m)-m q(c+m)\right]
\end{aligned}
$$

which, using (18), amounts to:

$$
F_{E} \geq f+3 \tau(m)+m q(c+m)-s .
$$

E's fee must therefore lie in the range

$$
f-m q(c+m) \geq F_{E} \geq f+3 \tau(m)+m q(c+m)-s,
$$

which is feasible only when $s \geq 3 \tau(m)+2 m q(c+m)=\psi(m)$, or $m \geq \hat{m}$.

Conversely, any pair of subscription fees $\left(F_{I}, F_{E}\right)$ satisfying $(18)$ and $(20)$ constitutes an equilibrium where $I$ corners the market. Among those equilibria, only one does not rely on weakly dominated strategies for $E$, and is therefore trembling-hand perfect, this is the one where $F_{E}=f-m q(c+m)$ and $F_{I}=f+s-\tau(m)-m q(c+m)$.

\section{G Proof of Proposition 3}

Let

$$
\pi^{F}(s)=\pi_{I}^{C}(\infty)=s-t+\Delta
$$

denote the maximal profit from foreclosure, and

$$
\pi^{S}(s)=\pi_{I}^{S}(0)=\frac{t}{2}\left(1+\frac{s}{3 t}\right)^{2}
$$

denote the profit from sharing the market under a cost-based access charge.

The function $\pi^{F}(s)$ increases linearly in $s$ whereas $\pi^{S}(0)$ increases quadratically in $s$; furthermore, for $s=0, \pi^{F}(0)<\pi^{S}(0)$. If follows that $\pi^{F}(s)$ lies above $\pi^{S}(s)$ in a range $s \in\left(s_{1}, s_{2}\right)$, where $s_{1}$ and $s_{2}$ are the two solutions to $\pi^{F}(s)=\pi^{S}(s)$, which are 
respectively given by

$$
s_{1}=3 t\left(2-\sqrt{1+2 \frac{\Delta}{t}}\right), s_{2}=3 t\left(2+\sqrt{1+2 \frac{\Delta}{t}}\right) .
$$

The second solution, $s_{2}$, exceeds the upper bound on the switching cost, $\bar{s}=3 t$, above which the market cannot be shared even with a cost-based access charge. By contrast, $s_{1}$ lies below this upper bound; it however still exceeds the lower bound on the switching cost, $\underline{s}=3(t-\Delta)$, below which the market would remain shared even with an infinite access charge. Therefore, in the relevant range $s \in[\underline{s}, \bar{s}]$, foreclosure is profitable (i.e., $\left.\pi_{I}^{C}(\infty)>\pi_{I}^{S}(0)\right)$ if and only if $s>s_{1}$.

\section{H Proof of Proposition 4}

Consider a candidate equilibrium in which $I$ corners the market. Marginal cost pricing then yields $p_{I}=c$; however, as no calls are originating from its network, $E$ may charge $p_{E} \neq c+m$. For $I$ to corner the market, it must be the case that even the consumers closest to $E$ favor $I$, that is, $v(c)-t-F_{I} \geq v\left(p_{E}\right)-s-F_{E}$, where $F_{I}$ and $F_{E}$ denote the candidate equilibrium fees. Furthermore, as $I$ maximizes its profit, this inequality cannot be strict; therefore:

$$
F_{I}=F_{E}-\left[t-v(c)+v\left(p_{E}\right)\right]+s .
$$

In addition, $E$ should not make any profit by stealing a few customers. The best such deviation involves $p_{E}^{\prime}=c+m$ (from marginal cost pricing) and a fee slightly below

$$
F_{E}^{\prime}=F_{E}-v\left(p_{E}\right)+v(c+m) .
$$

Such deviation is unprofitable if it generates a non-positive margin (taking into account the termination revenue that $E$ would receive from $I$ ), that is, only if:

$$
F_{E}^{\prime} \leq f-m q(c)
$$

Combining (21), (22) and (23) yields an upper bound on the profit that $I$ can achieve in a cornered market equilibrium:

$$
\pi_{I}^{C}=F_{I}-f \leq \bar{\pi}_{I}^{C}(m) \equiv s-[\tau(m)+m q(c)] .
$$

This expression is maximal for $m=0$, where it is equal to $\bar{\pi}_{I}^{C}(0)=s-t$. Therefore, when $s>\bar{s}=3 t$, in which case there is no shared-market equilibria and thus $I$ always corners 
the market, $I$ 's profit is maximal for $m=0 .{ }^{30}$ We now show that, when $s<\bar{s}, I$ cannot gain from departing from $m=0$ in order to corner the market. It suffices to show

$$
\pi_{I}^{C}(0)=s-t<\pi_{I}^{S}(0)=\frac{t}{2}+\frac{s}{3}\left(1+\frac{s}{6 t}\right)
$$

which amounts to: $\lambda(s) \equiv \frac{s}{3}\left(2-\frac{s}{6 t}\right)-\frac{3 t}{2}<0$. Since $\lambda(3 t)=0$ and $\lambda^{\prime}(s)>0$ (when $s<3 t$ ), it follows that $\lambda(s)<0$ for $s<\bar{s}=3 t$.

\section{References}

[1] Armstrong, M., 1998, 'Network Interconnection in Telecommunications,' Economic Journal, 108, pp. 545-564.

[2] Armstrong, M., 2002, 'The Theory of Access Pricing and Interconnection,' in Cave, M. E., Majumdar, S. K. and Vogelsang, I. (eds), Handbook of Telecommunications Economics (North-Holland, Amsterdam, The Netherlands).

[3] Armstrong, M. and Wright, J., 2009, 'Mobile Call Termination,' Economic Journal, 119, pp. F270-F307.

[4] Berger, U., 2005, 'Bill-and-Keep vs. Cost-Based Access Pricing Revisited,' Economics Letters, 86, pp. 107-112.

[5] Calzada, J. and Valletti, T., 2008, 'Network Competition and Entry Deterrence,' Economic Journal, 118, pp. 1223-1244.

[6] Cambini, C. and Valletti, T.M., 2008, 'Information Exchange and Competition in Communications Networks', The Journal of Industrial Economics, 56, pp. 707-728.

[7] Carter, M. and Wright, J., 2003, 'Asymmetric Network Interconnection,' Review of Industrial Organization, 22, pp. 27-46.

[8] De Bijl, P. W. J. and Peitz, M., 2002, Regulation and Entry into Telecommunications Markets (Cambridge University Press).

[9] De Bijl, P. W. J. and Peitz, M., 2004, 'Dynamic Regulation and Entry in Telecommunications Markets: A Policy Framework,' Information Economics and Policy, 16, pp. 411-437.

\footnotetext{
${ }^{30}$ It can be checked that the above-described cornered-market equilibrium indeed exists; in particular, second-order conditions are always satisfied for $m=0$.
} 
[10] ERG (2008), 'Common Position on symmetry of fixed call termination rates and symmetry of mobile call termination rates,' adopted by the ERG-Plenary on 28th February 2008, available at http://ec.europa.eu/danmark/documents/alle_emner/videnskabelig/090507_termi neringstakster_holdning_en.pdf.

[11] Gans, J. and King, S., 2001, 'Using 'Bill and Keep' interconnection arrangements to soften network competition,' Economics Letters, 71, pp. 413-420.

[12] Genakos, C. and Valletti, T., 2011, 'Testing the "Waterbed" Effect in Mobile Telephony,' Journal of the European Economic Association, 9, pp. 1114-1142.

[13] Grzybowski, L., 2008, 'Estimating Switching Costs in Mobile Telephony in the UK', Journal of Industry, Competition and Trade, 8, pp. 113-132.

[14] Grzybowski, L. and Pereira, P., 2011, 'Subscription Choices and Switching Costs in Mobile Telephony', Review of Industrial Organization, 38, pp. 23-42.

[15] Hoernig, S., 2007, 'On-net and Off-net Pricing on Asymmetric Telecommunications Networks,' Information Economics and Policy, 19, pp. 171-188.

[16] Hoernig, S. , Inderst, R. and Valletti, T., 2014, 'Calling Circles: Network Competition with Non-Uniform Calling Patterns,' The RAND Journal of Economics, 45, pp. $155-175$.

[17] Hurkens, S. and Jeon, D-S., 2012, 'Promoting Network Competition by Regulating Termination Charges,' International Journal of Industrial Organization, 30, pp. 541552.

[18] Hurkens, S. and López, Á.L., 2014, 'Mobile Termination, Network Externalities, and Consumer Expectations,' Economic Journal, 124, pp. 1005-1039.

[19] Jeon D.-S., Laffont, J.-J. and Tirole, J., 2004, 'On the Receiver Pays Principle,' The RAND Journal of Economics, 35, pp. 85-110.

[20] Jullien, B., Rey, P. and Sand-Zantman, W., 2013, 'Termination Fees Revisited,' International Journal of Industrial Organization, 31, pp. 738-750.

[21] Klemperer, P., 1987, 'The Competitiveness of Markets with Switching Costs,' The RAND Journal of Economics, 18, pp. 138-150.

[22] Laffont, J.-J., Rey, P. and Tirole, J., 1998a, 'Network Competition: I. Overview and Nondiscriminatory Pricing,' The RAND Journal of Economics, 29, pp. 1-37. 
[23] Laffont, J.-J., Rey, P. and Tirole, J., 1998b, 'Network Competition: II. Price Discrimination,' The RAND Journal of Economics, 29, pp. 38-56.

[24] López, Á.L., 2008, 'Using Future Access Charges to Soften Network Competition,' mimeo.

[25] López, Á.L., 2011, 'Mobile termination rates and the receiver-pays regime,' Information Economics and Policy, 23, pp. 171-181.

[26] López, Á.L. and Rey, P., 2012, 'Foreclosing Competition through Access Charges and Price Discrimination,' IDEI Working Paper, n. 570.

[27] Peitz, M., Valletti, T.M. and Wright, J., 2004, 'Competition in telecommunications: an introduction,' Information Economics and Policy, 16, pp. 315-321.

[28] Tangerås, T.P., 2014, 'Network Competition with Income Effects,' The RAND Journal of Economics, 45, pp. 645-673.

[29] Vogelsang, I., 2003, 'Price Regulation of Access to Telecommunications Networks,' Journal of Economic Literature, 41, pp. 830-862. 